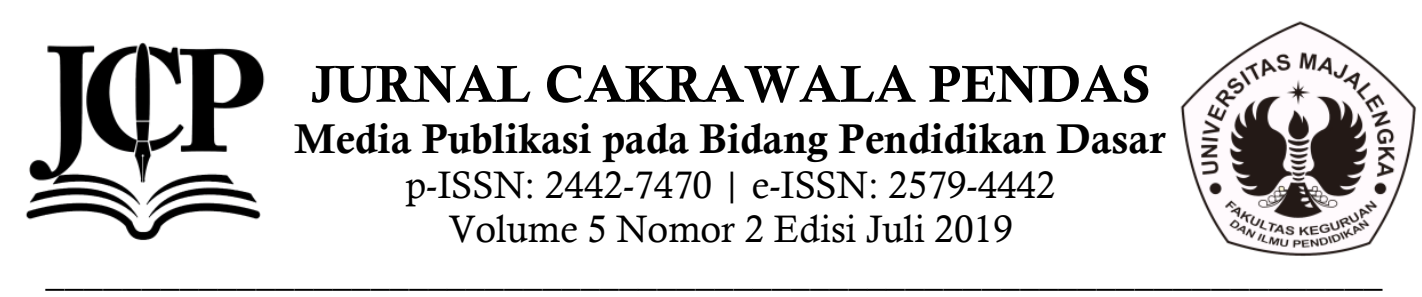

\title{
TEKNIK PEMBELAJARAN YANG EFEKTIF DALAM DISAIN PEMBELAJARAN KOOPERATIF UNTUK MATA PELAJARAN IPS
}

\author{
Ino Budiatman, Arry Patriasurya \\ Universitas Muhammadiyah Tangerang \\ ibudiatman@gmail.com, arry_azhar@yahoo.com
}

\begin{abstract}
Penelitian ini berupaya menemukan teknik yang paling efektif dari tiga teknik yang berbeda dalam metode kooperatif, yaitu: jigsaw, Numbered Head Together (NHT), dan Think Pair Share (TPS) dalam mempelajari mata pelajaran IPS. Penelitian ini dilaksanakan pada kelas 5 SDN di kota Tangerang, provinsi Banten. Sampel penelitian ditarik sebanyak 3 sekolah dengan teknik cluster random sampling. Masing-masing sampel diberikan teknik belajar yang berbeda sebanyak empat kali dengan topik yang sama sebelum mengukur hasil belajarnya. Hasil analisis data memperlihatkan terdapat perbedaan yang signifikan antara Jigsawdengan NHT dan TPS. Analisis lebih lanjut menginformasikan bahwa hasil belajar dengan teknik TPS memiliki angka yang lebih tinggi dibandingkan dengan NHT atau pun Jigsaw. Hasil penelitian menyimpulkan bahwa teknik TPS cenderung lebih efektif dalam meningkatkan hasil belajar siswa di antara ketiga teknik tersebut, disusul kemudian oleh NHT dan Jigsaw untuk mata pelajaran IPS.
\end{abstract}

Kata Kunci: Jigsaw, NHT, TPS, Hasil Belajar

\begin{abstract}
This research tries to find out which one is the most effective tecnique of cooperative learning between Jigsaw, Numbered Head Together (NHT) and Think-PairShare (TPS) in increasing students' learning achievement in social science subjects. The research is conducted in grade 5 of public elementary schools in Tangerang district of Banten Province. The sampel is three schools choosen by using cluster random sampling. Each of sample is taught same materials by using different techniquse for four times. Data analysis shows that there is a significant difference on students achievement before and after treatment. There is a significant difference on students achievement using jigsaw and NHT as well as TPS. Further analysis shows that TPS and NHT seem to be higher than jigsaw and they are different significantly. The research concludes that TPS technique tend to most effective to increase students achievement amog those three techniques and then is followed by NHT and Jigsaw in learning social science.
\end{abstract}

Keywords: Jigsaw, NHT, TPS, students achievement. 


\section{Pendahuluan}

Pembelajaran kooperatif (cooperative learning) merupakan metode pembelajaran yang berdaya besar dalam meningkatkan keterlibatan siswa, dukungan akademik, dan dukungan sosial terhadap keberhasilan peserta didik dalam mempelajari materi pelajaran. Sebagai metode pembelajaran yang menekankan pada kerjasama, saling membantu dan mendorong kegiatan diskusi dalam menyelesaikan tugas-tugas yang diberikan maka metode koperatif paling efektif diterapkan. Menurut Sunal dan Hans dalam Suyanto (2013:142) cooperatif learning memiliki pendekatan model yang khusus dirancang untuk memberikan dorongan kepada siswa agar mampu bekerja sama selama dalam proses pembelajaran berlangsung. Hasil kajian Slavin (1982: 22) menegaskan bahwa terdapat hubungan yang kuat antara metode pembelajaran kooperatif dengan hasil belajar, hubungan antar kelompok, harga diri, dan pengetahuan umum yang sedang berkembang pada masa itu. maka pembelajaran kooperatif memberikan penguatan terhadap proses pembelajaran di kelas.

Selanjutnya, sejalan dengan perkembangan pengetahuan, teknik pembelajaran dengan basis metode pembelajaran kooperatif juga mengalami perkembangan yang sangat pesat. Slavin (1982: 1) mengindentifikasi tidak kurang enam teknik pembelajaran yang berbasis pada metode pembelajaran kooperatif, yaitu: (a) Student Teams-Achievement Divisions (STAD), (b) Teams-GamesTournaments (TGT), (c) Team Assisted Individualization (TAI), (d) Jigsaw Learning Together Group, (e) Investigation dan (f) metode belajar lainnya. Sementara itu, Suprijono (2015: 108) memaparkan 12 metode pembelajaran kooperatif yang terangkum dalam metode pembelajaran aktif, inovatif, kreatif dan menyenangkan. hal ini berimplikasi bahwa metode pembelajaran tersebut dianggap mampu menciptakan pembelajaran yang dapat memotivasi siswa.

Sejak diperkenalkan, metode pembelajaran kooperatif telah menarik perhatian para kalangan peneliti dan akademisi. Pada tahun 2009, tidak kurang
1.200 penelitian terkait dengan metode pembelajaran kooperatif dan kebanyakan di antaranya menitik-beratkan pengaruh metode pembelajaran kooperatif terhadap hasil belajar atau perbandingannya dengan metode pembelajaran lainnya (Johnson \& Johnson, 2009: 38). Metode pembelajaran kooperatif, bahkan, tidak hanya digunakan dalam dunia akademik, tetapi juga dalam pelatihan kepemimpinan. Mereka yang dilatih dengan teknik pembelajaran kooperatif jigsaw - salah satu teknik pembelajaran berbasis metode kooperatif memperlihatkanpeningkatan yang signifikan dalam aspek professional kepemimpinan pesertanya. (Garcia, Abrego, dan Robert, 2017: 8). Dalam dunia akademik, Elyawati (2018: 66) menemukan bahwa teknik pembelajaran kooperatif jigsaw, dapat meningkatkan hasil belajar PKN siswa kelas V SD. Hal yang sama juga diungkapkan oleh Azmin (2016: 100) dan Nuraini (2019: 419) yang menemukan bahwa teknik pembelajaran kooperatif jigsaw, berpengaruh secara signifikan dengan hasil belajar.

Ellena dan Suminar (2018: 68) menyimpulkan bahwa teknik pembelajaran kooperatif Numbered-Head- Together (NHT) dapat secara efektif meningkatkan keterampilan sosial peserta didik pada jenjang Pendidikan Anak Usia Dini (PAUD), khususnya dalam aspek komunikasi, kerjasama, keterbukaan, empati, keterlibatan diri dan pengendalian diri. Untuk jenjang pendidikan dasar, penelitian terkait dengan pembelajaran kooperatif teknik NHT yang dilakukan Tobing (2019: 202) menyimpulkan bahwa penerapan metode koperatif NHT berhasil memperbaiki masalah rendahnya hasil belajar IPS padaSiswa SD. Relevan dengan temuan tersebut, Herwiyanti, Subroto dan Suprijono (2019 : 117) juga menyimpulkan bahwa metode belajar kooperatif teknik NHT dapat meningkatkan hasil belajar peserta belajar dalam bidang ilmu pengetahuan sosial. Selanjutnya, Hasil penelitian Tint dan Nyunt (2015: 10) menegaskan strategi Think-Pair-Share (TPS) sebagai salah satu teknik pembelajaran berbasis kolaboratif lainnya, memiliki pengaruh terhadap prestasi belajar pesertanya dalam mempelajari algoritma 
cluster K melalui penggunaan teknik belajar berbasis komputer. Temuan yang sama juga diperoleh melalui hasil penelitian yang dilakukan Kasmarni (2019: 303) untuk mata pelajaran IPA pada jenjang pendidikan dasar.

Upaya menemukan teknik belajar dalam metode pembelajaran kooperatif yang lebih efektif dalam meningkatkan hasil belajar dilakukan oleh Mokodompit dan Simanjuntak (2018: 14) yang menyimpulkan bahwa terdapat perbedaan sugnifikan antara teknik belajar kooperatif NHT dengan TPS dan teknik belajar TPS memperlihatkan kontribusi yang lebih besar terhadap hasil belajar membaca dalam bahasa Inggris. Kajian efektifitas teknik pembelajaran juga dilakukan oleh Mulyati (2018: 7) yang membandingkan antara teknik pembelajaran jigsaw dengan NHT dan menyimpulkan bahwa masing-masing teknik memiliki pengaruh positif terhadap hasil belajar persamaan linear dua variabel. Hanya saja, teknik pembelajaran NHT masih lebih efektif dibandingkan dengan teknik pembelajaran jigsaw untuk materi pelajaran tersebut. Selanjutnya, Suratno (2014: 33) menemukan bahwa teknik pembelajaran jigsaw lebih efektif dibandingkan TPS dalam meningkatkan hasil belajar matematika.

Penelitian ini diarahkan untuk mata pelajaran Ilmu Pengetahuan Sosial (IPS) karena, menurut Killen (2007: 81), metode pembelajaran kooperatif tidak hanya efektif untuk mata pelajaran sains, tetapi juga untuk mata pelajaran sosial. Subjek penelitiannya adalah siswa Sekolah Dasar (SD) dengan alasan bahwa pada jenjang pendidikan ini pesertanya lebih mudah untuk melakukan kerjasama dan masih memiliki sikap empati yang lebih tinggi. Untuk mengetahui teknik yang lebih efektif dalam mempelajari IPS, penelitian ini difokuskan pada tiga teknik pembelajaran berbasis metode kolaboratif, yaitu: (a) jigsaw; (b) NHT; dan (c) TPS.

Kerangka teoretis penelitian ini didasarkan atas temuan penelitian Novak dalam Vallori (2014: 202) yang menegaskan bahwa belajar yang penuh arti adalah dimana para pelajar berupaya mengintegrasikan pengetahuan baru dengan pengetahuan yang ada saat ini karena hal ini jauh lebih dari pada hanya mengingat atau menghapalkannya. Salah satu upaya untuk mengintegrasikannya adalah dengan berbagi pengalaman. Dalam konteks inilah metode belajar kooperatif dibangun. Metode belajar kooperatif adalah metode belajar yang merujuk pada paham konstruktivisme yaitu membangun pengetahuan dari pengalaman dan belajar dengan mengutamakan proses kerja sama antara kelompok peserta didik yang berbeda (Supriana,dkk., 2010: 8). Dalam belajar kooperatif, peserta belajar bekerjasama dalam sebuah kelompok kecil dalam sebuah aktivitas yang terstruktur, saling berhadapan dan belajar untuk bekerja sebagai sebuah tim (Adams, 2013: 66).

Belajar kooperatif dapat didefinisikan sebagai siswa bekerjasama untuk saling membantu dalam kelompok yang tidak dapat diperoleh melalui kerja sendiri atau secara berkompetisi (Slavin, 2010:4). Meskipun demikian, Adam (2013: 69) menekankan pentingnya menstrukturkan aktivitas agar proses belajar dapat berjalan secara lebih efektif. Melalui aktivitas yang terstruktur inilah para peserta belajar saling berbagi pengetahuan di dalam kelompoknya dan terus meluas di dalam kelasnya. Dengan demikian, belajar kooperatif pada dasarnya merupakan sebuah metode belajar yang menerapkan berbagai teknik untuk mendorong aktivitas belajar dan meningkatkan pemahaman peserta didik tentang materi pelajaran yang dibahas dengan menggunakan pendekatan terstuktur yang menghendaki peserta didik menciptakan, menganalisis, dan menerapkan konsep-konsep. (Kagan, 1990: 67).

Agar proses proses pembelajaran dikelas berjalan lebih efektif, mengutip pendapat Lundgren, Suyanto dan Jihad (2013:143) menyatakan terdapat 7 unsur dalam pembelajaran kooperatif yang perlu diperhatikan yaitu:

1) Siswa memiliki persepsi yang sama bahwa mereka tengelam dan berenang bersama

2) Siswa memliki tanggung jawab terhadap sisiwa lain dalam kelompoknya disamping tanggung jawab mereka terhadap diri sendiri dalam mempelajari materi yang sama 
3) Siswa harus memiliki pandangan bahwa mereka memiliki tujuan yang sama dalam kelompok

4) Siswa harus melakukan pembagian tugas dan tanggung jawab yang sama besar

5) Siswa akan diberi suatu evaluasi seluruh kelompok

6) Siswa berbagi kepemimpinan sementara mereka memperoleh keterampilan bekerja sama selama belajar

7) Siswa diminta mempertanggung jawabkan secara individual materi yang dipelajari dalam kelompok kooperatif.

Sedangkan Slavin, dkk (2013: 23) menyatakan bahwa metode yang terstruktur dengan baik seperti yang terdapat pada belajar kooperatif memiliki pengaruh positif terhadap ukuran hasil belajar dibandingkan dengan praktik pembelajaran lain meskipun menggunakan buku teks kurikulum yang inovatif sekalipun. Persoalannya kemudian adalah teknik yang dapat digunakan untuk melaksanakan metode belajar kooperatif ini sangat beragam sehingga perlu dibandingkan untuk memahami teknik mana yang lebih efektif dalam meningkatkan hasil belajar. Untuk memahami teknik-teknik yang dikaji dalam penelitian ini dapat diuraikan sebagai berikut.

\section{Teknik Jigsaw.}

Mengutip pendapat Adam (2013: 65) metode belajar kooperatif teknik jigsaw dikembangkan oleh seorang psikolog sosial Elliot Aronson pada tahun 1971. Teknik ini membagi peserta belajar dengan kompetensi yang berbeda ke dalam kelompok yang terdiri atas 4 sampai 5 peserta belajar. Kelompok ini kemudian dibagi lagi ke dalam kategori "pakar". Setelah selesai menyimpulkan materi pelajaran yang mereka pelajari, kelompok pakar dari masing-masing kelompok kemudian memperdalam kesimpulan yang telah mereka susun dalam kelompoknya masing-masing untuk kemudian dijelaskan ke dalam kelompoknya masing-masing.

Suprijono (2015: 109) menegaskan pembelajaran teknik belajar Jigsaw diawali dengan pengenalan sebuah materi berupa topik dengan menuliskannya pada papan tulis dan selanjutnya guru menjaring jawaban dari siswa untuk mengetahui siswa mana yang memahami topik tersebut. Mereka kemudian didistribusikan untuk setiap kelompok yang berjumlah 10 orang dan menjadi pakar di kelompoknya, sedangkan siswa lain dikategorikan sebagai kelompok tekstual Setelah masing-masing kelompok berdiskusi dan menyimpulkan apa yang mereka diskusikan di kelompoknya, para pakar ini kemudian dihimpun dalam satu kelompok untuk mendiskusikan kesimpulan yang mereka buat dalam kelompoknya masing-masing. Setelah mendapat kesimpulan akhir, mereka kembali ke kelompok asalnya untuk menjelaskan kesimpulan final yang mereka peroleh selama berdiskusi dengan pakar lainnya dan kemudian dipresentasikan dan diulas secara bersama-sama dan guru menutup sesi belajar tersebut dengan memberikan ringkasan terhadap materi tersebut.

\section{Teknik Numbered Heads Together}

Suprijono (2015: 109) menegaskan teknik Numbered Heads Together dilakukan dengan membagi siswa ke dalam kelompok kecil dan memberikan nomor untuk setiap anggota kelompok. Setelah guru memberikan topik yang akan dipelajari, setiap kelompok kemudian diberikan waktu berdiskusi untuk menyamakan pendapatnya (heads together) Langkah berikutnya guru menyebutkan nomor dan anggota tiaptiapkelompok dengan nomor yang sama harus mendeskripsikan atau menjawab pertanyaan yang diberikan guru.

\section{Teknik Think-Pair-Share.}

Teknik ini, menurut Success for All Foundation (2008: 11) dapat dilakukan dengan memberikan kesempatan kepada siswa untuk belajar berpasang-pasangan di dalam dan juga di luar kelompoknya. Pelajaran diawali dengan sebuah pertanyaan yang diberikan guru dan memberikan kesempatan kepada siswa untuk memikirkan jawabannya. Untuk memperkuat argumentasi jawaban ini, siswa dianjurkan untuk berdiskusi secara berpasang-pasangan di dalam kelompoknya. Jika pasangan ini masih belum yakin dengan jawabannya, mereka 
dapat berdiskusi dengan pasangan lain di dalam kelompoknya. Jika masih memerlukan bantuan, kelompok ini dapat berdiskusi dengan kelompok lain untuk mempertegas jawabannya dan kemudian mempresentasikan hasilnya di depan kelas. Guru, kemudian, memberikan ulasan terhadap materi yang sedang dipelajari sambil menutup kelas.

\section{Metode Penelitian}

Penelitian ini bertujuan untuk mengetahui perbedaan pengaruh metode belajar kooperatif dengan teknik belajar Jigsaw, NHT dan TPS terhadap hasil belajar IPS dan menggali teknik pembelajaran yang paling efektif di antara ketiganya dengan menggunakan pendekatan kuantitatif. Disain penelitiannya adalah eksperimen murni (true experiment) dengan perlakuan yang berbeda terhadap subjek penelitian.

Populasi penelitian adalah SD

Negeri di Kota Tangerang yang berjumlah sebanyak 394, sampel penelitiannya adalah kelas $\mathrm{V}$ pada tiga SDN yang ditarik dengan teknik cluster random sampling. Masingmasing SD, kemudian, diberikan perlakuan sebanyak empat kali pertemuan dengan teknik yang berbeda. Sekolah A dengan jumlah siswa sebanyak 39 orang diberikan perlakuan dengan teknik Jigsaw, sekolah B denganjumlah 30 orang siswa teknik NHT, dan sekolah $\mathrm{C}$ dengan jumlah siswa 31 orang diperlakukan dengan teknik TPS. Materi yang diajarkan disesuaikan dengan materi padatema 8 - 11 pada kurikulum 2013 setelah terlebih dahulu berkonsultasi dengan guru kelasnya.

Perlakuan diberikan dengan teknik dengan membagikan peserta belajar dalam kelompok yang terdiri dari 5 siswa. Masingmasing kelompok terdiri atas $1-2$ siswa yang memperoleh angka $\geq 8$ untuk mata pelajaran IPS di rapornya, $2-3$ siswa dengan nilai $<8$, tetapi $>7$, dan 2 orang dengan angka $<7$.

Masing-masing kelompok diberikan fuzzle untuk disusun, kemudian diberikan waktu untuk mendiskusikan materi yang terdapat dalam fuzzle tersebut dan mendeskripsikannya. Hasilnya kemudian dipresentasikan di depan kelas. Peserta yang mempresentasikannya adalah salah satu dari anggota kelompok melalui kesepakatan kelompoknya. Untuk teknik NHT, setiap anggota kelompok diberi nomor dari 1 sampai 5 atau enam. Mereka diberikan waktu untuk mendiskusikan materi yang terdapat dalam fuzzle dan mendeskripsikannya. Pada akhir sesi pelajaran, guru menyebutkan salah satu nomor dari $1-5$ dan setiap anggota kelompok yang nomornya sama harus mempresentasikan hasil diskusi kelompoknya. Untuk teknik TPS, setiap kelompok dipecah menjadi berpasangpasangan yang terdiri atas $2-3$ siswa. Mereka kemudian, diberikan fuzzle untuk disusun dan mendeskripsikannya. Jika pasangan ini masih ragu, mereka dapat berdiskusi dengan pasangan lain di dalam kelompoknya. Jika juga masih ragu, mereka dapat berdiskusi dengan pasangan dari kelompok lain atau kelompok lain untuk saling bertukar informasi tentang topik yang sedang dibahas.

Pada akhir perlakuan peserta diuji dengan menggunakan seperangkat alat tes yang telah diuji validitas dan reliabilitasnya. Pengukuran validitasnya menggunakan $r$ product moment dan berhasil menjaring 20 butir tes dengan koefisien reliabilitas KR 20 sebesar 0,84 . Butir-butir tes ini digunakan sebanyak 20 butir dan digunakan untuk prestest dan postest. Analisis data dilakukan dengan menggunakan one way Anova within treatment dan post hoc test.

\section{Hasil Penelitian}

Hasil pretest untuk kelompok sampel yang diuji dapat digambarkan sebagai berikut.

Tabel 1. Uji Hasil Pretest

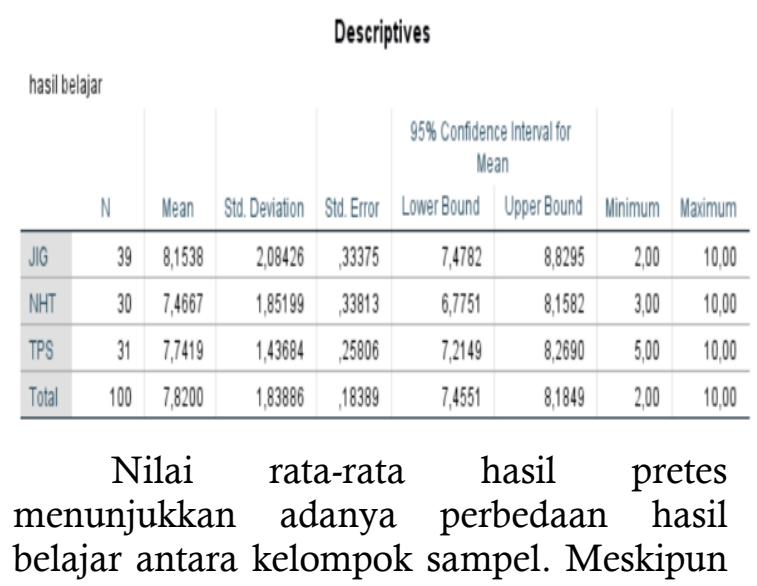


demikian, perbedaan ini harus diuji untuk melihat signifikansinya melalui uji ANOVA. Uji ini dimaksudkan untuk melihat signifikansi perbedaannya. Hasil Analisis data SPPS untuk uji ini dapat dilihat sebaga berikut.

Tabel 2. Uji Signifikansi Hasil Pretest

\section{ANOVA}

\begin{tabular}{l|r|r|r|r|r} 
hasil belajar & $\begin{array}{c}\text { Sum of } \\
\text { Squares }\end{array}$ & df & Mean Square & \multicolumn{1}{c|}{ F } & Sig. \\
\hline Between Groups & 8,281 & 2 & 4,140 & 1,230 &, 297 \\
\hline Within Groups & 326,479 & 97 & 3,366 & & \\
\hline Total & 334,760 & 99 & & & \\
\hline
\end{tabular}

Berdasarkan hasil olah data di atas, harga $\mathrm{F}$ hitung untuk mengetahui perbedaan angka rata-rata ini adalah 1,230 dengan sig $=0,297$ dan harga sig ini $>0,05$. Hal ini menegaskan bahwa tidak ada perbedaan yang signifikan hasil belajar untuk ketiga kelompok sampel karena harga sig $>$ dari 0,05.

Setelah peserta diberikan perlakuan yang berbeda dengan menerapkan teknik belajar yang berbeda selama empat minggu berturut-turut, pencapain hasil belajar mengalami perubahan yang cenderung mengalami peningkatan. Hasil analisis SPSS untuk uji post test ini dapat dilihat di bawah ini.

Tabel 3. Uji Hasil Post test

\begin{tabular}{|c|c|c|c|c|c|c|c|c|}
\hline & & & & Desc & riptives & & & \\
\hline & & & & & & & & \\
\hline & & & Std. & Std. & $95 \%$ Confidence & Interval for Mean & Minim & Maximu \\
\hline & $\mathrm{N}$ & Mean & Deviation & Error & Lower Bound & Upper Bound & um & $\mathrm{m}$ \\
\hline JIG & 39 & 15,9487 & 1,52088 & 24354 & 15,4557 & 16,4417 & 12,00 & 19,00 \\
\hline NHT & 30 & 16,4667 & 1,61316 & ,29452 & 15,8643 & 17,0690 & 13,00 & 19,00 \\
\hline TPS & 31 & 17,2258 & 1,05545 & 18956 & 16,8387 & 17,6129 & 15,00 & 19,00 \\
\hline Total & 100 & 16,5000 & 1,50756 & 15076 & 16,2009 & 16,7991 & 12,00 & 19,00 \\
\hline
\end{tabular}

Hasil analisis melalui aplikasi SPSS di atas memperlihatkan adanya kenaikan hasil belajar sebelum dan sesudah mendapat perlakuan. Meskipun demikian, perbedaannya cenderung berbeda antara semua teknik yang digunakan. Masingmasing teknik mengalami perubahan yang cenderung meningkat untuk semua teknik yang diterapkan. Untuk mengetahui signifikansi perubahan ini dapat dilakukan melalui uji ANOVA dan hasilnya dapat digambarkan sebagai berikut.
Tabel 2. Uji Signifikansi Hasil Post test

\section{ANOVA}

\begin{tabular}{lrr|r|r|r} 
Hasil belajar & & & & & \\
& Sum of Squares & df & Mean Square & F & Sig. \\
\hline Between Groups & 28,217 & 2 & 14,108 & 6,954 &, 002 \\
\hline Within Groups & 196,783 & 97 & 2,029 & & \\
\hline Total & 225,000 & 99 & & & \\
\hline
\end{tabular}

Tabel di atas menegaskan bahwa harga $\mathrm{F}=$ 6,954 dengan sig $=0,002<0,05$ yang berarti terdapat perbedaan yang signifikan antara teknik jigsaw, NHT, dan TPS. Dengan kata lain, penerapan teknik belajar Jigsaw, NHT, dan TPS memiliki perbedaan dalam meningkatkan hasil belajar IPS. Jika disusun dalam bentuk berpasangan, perbedaannya dapat dilihat melalui uji Turkey berikut.

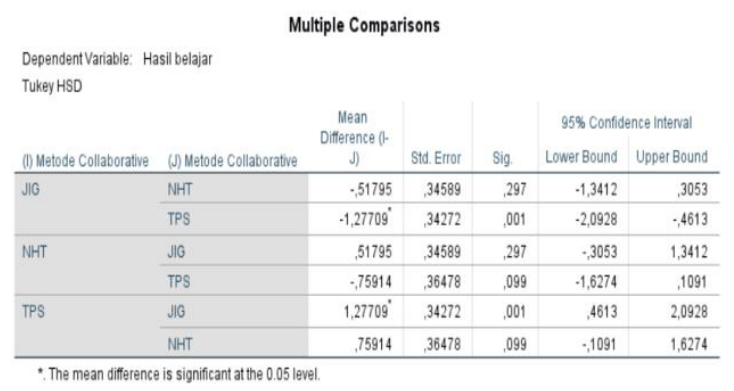

Hasil analisis di atas menggambarkan bahwa terdapat perbedaan yang signifikan antara teknik Jigsawdengan TPS, yang ditandai dengan harga sig 0,01 $<0,05$. Jigsaw dengan NHT cenderung tidak berbeda secara signifikan karena harga sig $=$ $0,97>0,05$. Demikian pula dengan NHT dan TPS yang memiliki angka 0,09 > 0,05. Untuk sementara, teknik yang paling efektif dalam meningkatkan hasil belajar IPS adalah TPS karena memiliki pengaruh yang berbeda dibandingkan dengan teknik lainnya. Selanjutnya, untuk mendapatkan efektivitas ketiga teknik tersebut dalam meningkatkan hasil bejajar IPS, dilakukan uji Turkey berikut.

\section{Hasil belajar}

Tukey HSD

Subset for alpha $=0.05$

\begin{tabular}{l|r|r|r} 
Metode Collaborative & \multicolumn{1}{c}{ N } & \multicolumn{1}{c}{1} & \multicolumn{1}{c}{2} \\
\hline JIG & 39 & 15,9487 & \\
\hline NHT & 30 & 16,4667 & 16,4667 \\
\hline TPS & 31 & & 17,2258 \\
\hline Sig. & &, 308 &, 083 \\
\hline
\end{tabular}


Sesuai dengan hasil analisis data di atas, jika diurutkan dari yang terbesar, hasil belajar dengan teknik TPS memiliki angka rata-rata 17,23, NHT sebesar 16,47, dan Jigsaw sebesar 15,95. Merujuk pada angkaangka tersebut, teknik belajar yang paling efektif di antara ketiga teknik dalam metode belajar kooperatif untuk meningkatkan hasil belajar IPS adalah teknik TPS, disusul dengan teknik NHT dan disusul kemudian dengan teknik Jigsaw. Dengan kata lain, peningkatan hasil belajar IPS dengan menggunakan teknik TPS lebih tinggi dari pada dengan teknik Jigsaw dan NHT. Pada sisi lain, Meskipun NHT memiliki angka yang relatif lebih tinggi dari pada Jigsaw, perbedaan keduanya tidaklah signifikan.

Temuan di atas menegaskan bahwa metode pembelajaran kooperatif dengan teknik Jigsaw, NHT dan TPS pada dasarnya memiliki pengaruh terhadap terhadap hasil belajar IPS. Ketiga teknik ini cukup efektif dalam meningkatkan hasil belajar. Hanya saja jika dibandingkan untuk mengetahui teknik yang paling efektif dalam meningkatkan hasil belajar, maka diperoleh gambaran sebagai berikut. Dari ketiga teknik yang diuji, posisi pertama ditempati oleh teknik TPS dan memiliki perbedaan yang signifikan dibandingkan dengan Jigsaw dan NHT. Posisi kedua ditempati oleh NHT meskipun perbedaannya dengan teknik Jigsaw tidak berbeda secara signfikan. Posisi terkahir ditempati oleh Jigsaw yang memiliki varians yang cenderung sama dengan NHT.

Sejalan dengan temuan Mokodompit dan Simanjuntak (2018: 14) yang menyimpulkan teknik belajar kooperatif TPS lebih efektif dari pada NHT dalam belajar membaca dalam bahasa Inggris. Temuan penelitian ini juga sejalan dengan hasil penelitian Mulyati (2018: 7) yang menyimpulkan bahwa teknik pembelajaran NHT lebih efektif dibandingkan dengan teknik pembelajaran jigsaw. Meskipun demikian, hasil penelitian ini berbeda dengan Suratno (2014: 72) menemukan bahwa teknik pembelajaran jigsaw lebih efektif dibandingkan TPS dalam meningkatkan hasil belajar matematika.

Perbedaan tersebut pada dasarnya dapat dipahami karena mata pelajaran yang dikaji sangat berbeda. Untuk mata pelajaran IPS, makin banyak sumber belajar dari rekan sekelas, makin banyak pula informasi valid yang diperoleh. Sebaliknya, untuk mata pelajaran yang harus menghafal rumus-rumus seperti mata pelajaran matematika, penggunaan teknik TPS ini membuat peserta belajar memperoleh informasi yang berbeda dari kelompoknya. Kondisi inilah yang membuat peserta belajar ini menjadi kurang percaya diri dalam menjawab pertanyaan-pertanyaan. Lain halnya, dengan mata pelajaran IPS, makin banyak, informasi ang diperoleh, makin tinggi rasa percaya diri peserta belajar dalam menjawab pertanyaan.

Temuan penelitian ini juga mendukung pernyataan Killen (2007: 81) yang menegaskan bahwa metode pembelajaran kooperatif tidak hanya efektif untuk mata pelajaran sains, tetapi juga untuk mata pelajaran sosial. Mata pelajaran yang dikaji dalam penelitian ini adalah mata pelajaran sosial dan temuannya tidak jauh berbeda dengan peneliti tersebut. Sesuai namanya, IPS adalah mata pelajaran menghendaki wawasan yang luas agar dapat memahaminya dengan baik. Wawasan ini terdapat pada masing-masing siswa yang terlibat di dalamnya. Dengan menerapkan metode belajar kooperatif, masing-masing siswa dapat berkontribusi dalam memperluas wawasan kelompoknya dengan cara ikut menyumbangkan apa yang diketahuinya. Hal ini tentu saja akan berakhir dengan tumpukan pengetahuan dengan berbagai perspektif. Dalam konteks inilah, para siswa memperluas wawasannya sehingga mampu memahami apa yang dipahami oleh siswa lainnya.

Salah satu kelebihan metode kolaboratif dibandingkan metode lainnya terletak pada struktur aktivitasnya (Adam, 2013: 69) Aktivtas ini distrukturkan dan menjadi teknik belajar dalam kerangka metode kooperatif. Teknik belajar Jigsaw, misalnya, aktivitas siswa disusun dalam bentuk kelompok kecil untuk memecahkan sebuah permasalahan. Kelompok ini kemudian saling berbagi pengetahuan. Hanya saja tekanan terhadap kelompok ini relatif kurang dibandingkan dengan teknik lain. Hal ini memungkinkan anggota kelompok tidak optimal dalam memahami 
apa yang didiskusikan dalam kelompok tersebut. Berbeda halnya dengan teknik NHT, tekanan yang dialami anggota kelompok relatif lebih besar sehingga setiap individu dalam kelompok berupaya memahami apa yang didiskusikan untuk tidak mempermalukan kelompoknya. Yang lebih ekstrim, tentunya, TPS karena tekanan dialami anggota kelompok semakin menjurus hanya pada dua atau tiga siswa. Di samping itu, pola komunikasi antara pasangan-pasangan dalam kelompok ini relatif lebih kecil sehingga mereka dapat saling bertukar pikiran dengan leluasa. Untuk tidak mempermalukan kelompoknya, pasangan ini juga memiliki ruang untuk berdiskusi dengan pasangan lain dalam kelompok atau di luar kelompoknya. Hal inilah yang, barangkali, menjadi kunci jawaban kenapa teknik TPS menjadi yang paling efektif di antara ketiga teknik belajar yang dikaji dalam penelitian ini.

Hanya saja asumsi ini masih perlu diteliti lebih lanjut untuk mengetahui pengaruh tekanan dan pola komunikasi terhadap hasil belajar. Ini diperlukan karena tidak mustahil tekanan dan pola komunikasi ini dapat menjadi variabel antara yang dapat diandalkan untuk meningkatkan hasil belajar. Dengan demikian, untuk penelitian selanjutnya, perlu dikaji beberapa variabel antara yang dapat mempengaruhi hasil belajar melalui metode belajar kooperatif.

\section{Kesimpulan}

Berdasarkan hasil analisis data sebelumnya, dapat disimpulkan hal-hal sebagai berikut:

1. Metode belajar kooperatif teknik Jigsaw, NHT, dan TPS, pada dasarnya, dapat diandalkan untuk meningkatkan hasil belajar mata pelajaran IPS;

2. Meskipun sama-sama berpengaruh terhadap hasil belajar mata pelajaran IPS, terdapat perbedaan antara ketiga teknik tersebut

3. Teknik IPS berbeda secara signifikan dengan teknik belajar jigsaw dan NHT;

4. Teknik belajar NHT memiliki perbedaan yang tidak signifikan dengan teknik belajar Jigsaw sehingga dapat dikatakan bahwa kedua teknik ini memiliki kecenderungan yang sama dalam mempengaruhi hasil belajar IPS dan dapat saling dipertukarkan;

5. Jika dibandingkan, di antara ketiga teknik tersebut, teknik TPS adalah teknik belajar yang paling efektif dalam meningkatkan hasil belajar mata pelajaran IPS, disusul kemudian dengan teknik NHT, dan jigsaw.

Berdasarkan kesimpulan di atas, untuk mata pelajaran IPS dan rumpun mata pelajaran sosial lainnya, disarankan untuk lebih banyak menggunakan teknik belajar TPS dan NHT karena teruji secara empiris lebih efektif dalam meningkatkan hasil belajar.

\section{Daftar Pustaka}

Adams, Francis Hull (2013) Using Jigsaw Technique As An Effective Way Of Promoting Cooperative Learning Among Primary Six Pupils In Fijai. International Journal Of Education And Practice, 2013, 1(6):64-74

Arató, Ferenc dan Aranka Varga. (2015) $A$ Handbook for learning together - an introduction to co-operative learning, Róbert Marcz and Berta Bakony (trans.) Pecs: University of Pécs, Faculty of Humanities, Institute of Education Sciences

Azmin, Nur Hafizah (2016) Effect of the Jigsaw-Based Cooperative Learning Method on Student Performance in the General Certificate of Education Advanced-Level Psychology: An Exploratory Brunei Case Study. International Education Studies Vol. 9, No. 1.

Ellena, Raissa Citra dan Dewi Retno Suminar, (2018) Effectiveness Cooperative Learning Numbered Heads Together to Improve the Social Skills of Kindergarten's Student. The International Journal of Social Science and Invention Vol 5 No 1

Garcia, Alejandro, Jesus Abrego, dan Reguenes Robert (2017)Using the Jigsaw Method for Meaningful 
Learning to Enhance Learning and Rentention in an Educational Leadership Graduate School Course. Global Journal of Human-Social Science: G Linguistics \& Education Volume 17 Issue 5

Herwiyanti, Ratna Dwi dan Waspodo Tjipto Subroto, Agus Suprijono (2019) Implementation of Cooperative Learning Model in Numbered Heads Together for Improving 4th Grade Students Learning Achievement on Social Science, IOSR Journal of Research \& Method in Education Volume 9, Issue 1 Ser. II.

Johnson, D.W., dan Johnson R, T. (2009). An Educational Psychology Success Story- Social Interdependence Theory and Cooperative Learning. Educational Researcher, 38, (5), 365377

Johnson, D.W., R.T. Johnson and E.J. Holubec, 1986. Circles of learning: Cooperation inthe classroom. Edina, $\mathrm{MN}$ : Interaction Book Company.

Kagan, S. (1990) Educational leadership. http://home.capecod.net/ tpanitz/t edsarticles/coopdefinition.htm.

Kasmarni (2019) Penerapan Model Pembelajaran Kooperatif Tipe Think Pair Share Untuk Meningkatkan Hasil Belajar IPA Siswa Kelas IV SD Negeri 004 Seberang Teluk Hilir Kecamatan Kuantan Tengah Kabupaten Kuantan Singingi. Jurnal PAJAR (Pendidikan dan Pengajaran) Vol 3 (2) DOI: http://dx.doi.org/10.33578/pjr.v3i2. 7020, pp 297 - 305

Killen, R. (2007). Effective Teaching Strategies for OBE Teaching. (2nd, Ed). Boston: Social Science Press.

L. Tobing, Rosita, (2019) Meningkatkan Hasil Belajar IPS Siswa Kelas Vc SD Negeri 164 Pekanbaru dengan Menggunakan Metode Pembelajaran Kooperatif Numbered Heads Together (NHT). Jurnal PAJAR (Pendidikan dan Pengajaran) Vol3 (1), pp 197 205
Mokodompit, Prisilia L. dan Debora ChaterinSimanjuntak (2018). Enhancing Students' Reading Comprehension Ability Through Comparison Study Between Cooperative Learning Numbered Heads Together (NHT) And ThinPair-Share (TPS) Strategies. thesis. Bandung: Universitas Advent

Mulyati, Sri, (2018) Pengaruh Strategi Pembelajaran Kooperatif Tipe Jigsaw Dan Numbered Heads Together (NHT) terhadap Hasil Belajar Siswa Pada Sistem Persamaan Linear DuaVariabel. Skripsi. Program Studi Pendidikan Matematika Fakultas Keguruan Dan Ilmu Pendidikan Universitas Muhammadiyah Surakarta

Nurani, Zun (2019) Penggunaan Metode Jigsaw Untuk Meningkatkan Aktivitas dan Hasil Belajar Sejarah Pokok Bahasan Perkembangan Pemerintahan Orde Baru Siswa Kelas Xii IPS SMA Negeri 10 Pekanbaru. Jurnal PAJAR (Pendidikan dan Pengajaran)Vol 3 (2) DOI: http://dx.doi.org/10.33578/pjr.v3i2. 6828, pp 418-424

Sanjaya,Wina (2011) Strategi Pembelajaran Berorentasi Standar Proses pendidikan. Jakarta: Kencana Prenada Media.

Slavin, Robert E. (1982) Cooperative learning. Cooperative Learning: Student Teams. What Research Says to the Teacher. Washington, D.C: National Education Association.

Slavin, Robert E. (2010) Cooperative Learning: Teori, Riset, dan Praktik. Bandung: Nusa Media

Slavin, Robert E., dkk. eds (2013)Learning to Cooperate, Cooperating to Learn. New York: Springer Science+Business Media, LLC

Success for All Foundation (2008) Cooperative Learning. Baltimore: Success for All Foundation.

Success for All Foundation (2010) PowerTeaching Cooperative 
Learning Handbook. Baltimore: Success for All Foundation.

Supriana, Nana,dkk. (2010) Pendidikan IPS. Bandung: UPI Press.

Suprijono, Agus (2015) Cooperative Learning Teoridan Aplikasi Paikem. Yogyakarta: Pustaka Pelajar.

Suratno (2014) Keefektifan Pembelajaran Tipe TPS dan JIGSAW Ditinjau dari Prestasi Belajar Matematika dan Karakter Siswa. $\quad$ PYTHAGORAS: Jurnal Pendidikan Matematika Volume 9 - Nomor 1, Juni, (70-78)

Suyanto dan Asep Jihad (2013) Menjadi Guru Profesional. Jakarta: Erlangga

Tint, San Sandan EiEi Nyunt, (2015) "Collaborative Learning With Think Pair -Share Technique" dalam Computer Applications: An International Journal (CAIJ), Vol.2, No.1.

Vallori, Antoni Ballester, (2014) Meaningful Learning in Practice. Journal of Education and Human development, Vol. 3, No. 4. pp. 199209,(online),(http://dx.doi.org/10.15 640/jehd.v3n4a18) diakses 29 Mei 2019 